\title{
The Immersion Corrosion Resistance of Shot Peening and MAO Applied on AZ31-0.5\% La Sheets
}

\author{
Galal Elmansouri \\ Metallurgical and Materials Engineering Department \\ Karabuk University \\ Karabuk, Turkey \\ galal_mansouri@yahoo.com \\ Hayrettin Ahlatci \\ Metallurgical and Materials Engineering Department \\ Karabuk University \\ Karabuk, Turkey \\ hahlatci@karabuk.edu.tr
}

\author{
Ismail Hakki Kara \\ Metallurgical and Materials Engineering Department \\ Karabuk University \\ Karabuk, Turkey \\ ihakkikara@karabuk.edu.tr \\ Yunus Turen \\ Metallurgical and Materials Engineering Department \\ Karabuk University \\ Karabuk, Turkey \\ yturen@karabuk.edu.tr
}

\begin{abstract}
In this study, the effect of Shot Peening (SP) and Micro Arc Oxidation (MAO) process on the corrosion resistance of $0.5 \%$ La with added AZ31 Mg alloy, hot rolled at different rolling speeds, was investigated. It was found that the surface of the rolled material at a rolling speed of $4.7 \mathrm{~m} / \mathrm{min}$ had higher surface smoothness values than the one rolled at $10 \mathrm{~m} / \mathrm{min}$. It was observed that the corrosion rate changed in the first 40 of 168 hours. In the following hours, the corrosion rate showed different results according to the initial microstructure properties of the base materials. Initially, pore size was the dominant factor determining corrosion resistance, although, after coating, the corrosion rate was affected by the twins formed, based on rolling speed, which enhanced the corrosion rate between 48 and 168 hours.
\end{abstract}

Keyword-shot peening; micro arc oxidation; AZ31; La; hot rolling; corrosion resistance

\section{INTRODUCTION}

$\mathrm{Mg}$ alloys attract attention especially from the automotive and aerospace industries due to their low density and high strength [1]. HCP (hexagonal package structure) reduces the easy forming of $\mathrm{Mg}$ alloys and weakens the competitiveness of sheet $\mathrm{Mg}$ products [2]. It is known that rare earth elements increase the formability of AZ31 Mg alloy [3]. On the other hand, the corrosion resistance of $\mathrm{Mg}$ alloys is poor and coating and alloying in order to improve corrosion resistance are quite popular [4-5]. Moreover, it is desired to improve the mechanical properties of $\mathrm{Mg}$ alloys by creating tension on the surface of the material by processes such as shot peening (SP) [6]. In addition, the micro arc oxidation (MAO) process improves corrosion resistance perfectly [7]. AZ31 Mg alloys which have been treated with only SP or MAO have been reported [4-6]. The aim of this study is to improve the corrosion resistance of AZ31 Mg alloy metal sheets by addition of $\mathrm{La}$ as well as SP and MAO applications. In addition, the effect of rolling speed and rolling parameters on the final result was investigated.

\section{EXPERIMENTAL STUDY}

AZ31 $\mathrm{Mg}$ alloys containing $0.5 \mathrm{La}$ (\%wt.) were produced by using low pressure gravity die casting method. The composition of the produced material, determined by an XRF machine, was $3.11 \%$ wt $\mathrm{Al}, 1.06 \%$ wt $\mathrm{Zn}, 0.23 \% \mathrm{wt} \mathrm{Mn}$, and $0.54 \%$ wt La. In an argon gas protected environment, pure $\mathrm{Mg}$ alloys were allowed to melt at $750^{\circ} \mathrm{C}$ for 1 hour and then the La-Mg master alloy was added to the ladle and alloyed. In $\mathrm{SF}_{6}-$ $\mathrm{CO}_{2}$ blended protective atmosphere, the alloy was transferred with $2 \mathrm{~atm}$ pressure to a stainless steel $36 \times 36 \times 200 \mathrm{~mm}$ mold which was heated at $350^{\circ} \mathrm{C}$. Billets with dimensions $36 \times 12 \times 80 \mathrm{~mm}$ were cut from the billets left to cool in the molds to be used in the homogenization process before rolling. The surfaces of the billets were homogenized for 24 hours at $400^{\circ} \mathrm{C}$ and were sanded with 800 sanding sheets before rolling. Before rolling the specimens were heat treated at $400^{\circ} \mathrm{C}$ for $30 \mathrm{~min}$. The samples were rolled at $400^{\circ} \mathrm{C}$. The thickness of billets reduced from $12 \mathrm{~mm}$ to $2 \mathrm{~mm}$ in 5 passes and they were allowed to cool in air after the last pass. The rolling parameters were $15 \%$ cross-sectional redultion per pass and the rolling speeds were $4.7 \mathrm{~m} / \mathrm{min}$ and $10 \mathrm{~m} / \mathrm{min}$. The used rollers of the rolling stand were from stainless steel with a diameter of $110 \mathrm{~mm}$. No lubricant was used in the rolling process. The SP process was carried out for $20 \mathrm{~min}$ with TAB company ball SP machine by using Z850 metal balls on the sheet materials which were previously sanded with 1200 grit by giving maximum 8 bar air pressure according to AISI 1070 standard. After the SP process, the surface of the samples was cleaned with alcohol and dried. Micro arc oxidation process followed: $25 \times 25 \times 12 \mathrm{~mm}$ samples previously sanded up and cleaned with ultrasonic cleaning device were immersed in $4 \mathrm{~g} / \mathrm{lt}$ sodium silicate, $1 \mathrm{~g} / \mathrm{lt}$ potassium hydroxide and $3 \mathrm{~g} / \mathrm{lt}$ disodium hydrogen phosphate containing $41 \mathrm{t}$ pure water medium under $85 \mathrm{~mA} / \mathrm{cm}^{2}$ current 
density and $250 \mathrm{~Hz}$ frequency for $5 \mathrm{~min}$. Immersion corrosion test in $3.5 \% \mathrm{NaCl}$ solution was applied to the $2 \mathrm{~mm}$ sheets for 168 hours. After the corrosion test, the corrosion waste of the samples were extracted using chromic acid solution and then dried with alcohol and the weight loss was measured using 0.0001 precision balance machine. Microstructure images of the samples were taken before and after the corrosion test by SEM (Carl Zeiss Ultra Plus Gemini Fesem). In addition, information was obtained about thesecondary phases by using XRD (RIGAKU Ultima IV). The surface smoothness of the samples was measured according to the ISO 1997 standard (Mitutoya Surftest SV-2100M4).

\section{RESULTS AND DISUSSION}

\section{A. Microstructure Results}

As shown in Figure 1, the base metal of AZ31-0.5 La alloys rolled at $4.7 \mathrm{~m} / \mathrm{min}$ had twins dominated microstructure and bigger sized secondary phases shaped as globular, although the rolled at $10 \mathrm{~m} / \mathrm{min}$ speed specimen includes dynamic recrystallization grains and finer secondary phases distributed mostly continuously on grain boundaries. As shown in Figure 2 , surface morphology and cross-sectional images of the samples after MAO treatment are different. However, the typical coating properties of the MAO process were obtained, for example, from islets of different sizes and micropores of different diameters formed on these islets. Melting and rapid solidification during MAO ensure that the pores are circular. At a rolling speed of $4.7 \mathrm{~m} / \mathrm{min}$, the extruded sample has smaller diameter micropores, which are more dense in the islets. The rolled material at $10 \mathrm{~m} / \mathrm{min}$ has larger pores with larger diameters, but they are distributed less on the islets.

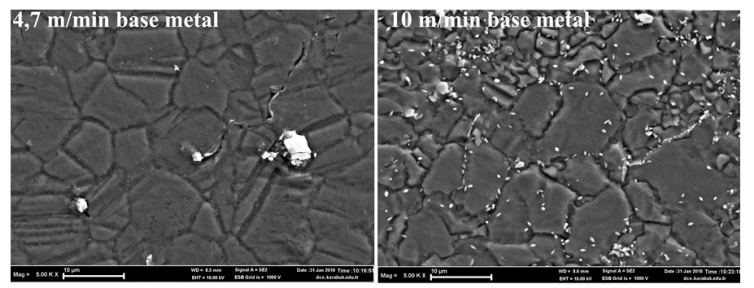

Fig. 1. SEM images of base metals rolled at 4.7 and $10 \mathrm{~m} / \mathrm{min}$

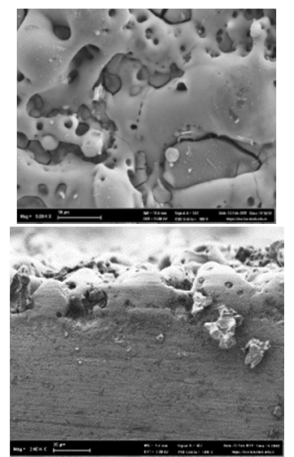

(a)

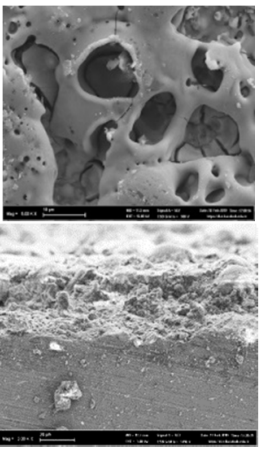

(b)
Fig. 2. SEM images of surface and cross-section of materials rolled at: (a) $4.7 \mathrm{~m} / \mathrm{min}$, (b) $10 \mathrm{~m} / \mathrm{min}$
The images taken show us that the rolled material at $4.7 \mathrm{~m} / \mathrm{min}$ is coated non-uniformly. The coating is more uniform at $10 \mathrm{~m} / \mathrm{min}$. The XRD results of the rolled material at a rolling speed of $4.7 \mathrm{~m} / \mathrm{min}$ coated with $\mathrm{MAO}$ are given in Figure 3. It is seen that the coating contains $\mathrm{MgO}$ and $\mathrm{MgAl}_{2} \mathrm{O}_{4}$ phases.

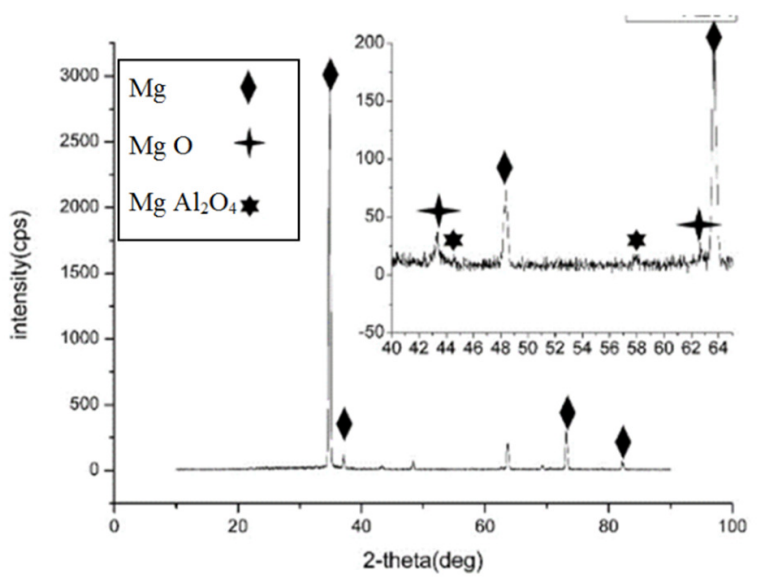

Fig. 3. XRD paterns of MAO coated material rolled at $4.7 \mathrm{~m} / \mathrm{min}$

\section{B. Surface Smoothness}

As can be seen from Figure 4, the surface images of the samples after coating are similar. However, surface smoothness was found to be lower in the material rolled at $10 \mathrm{~m} / \mathrm{min}$.

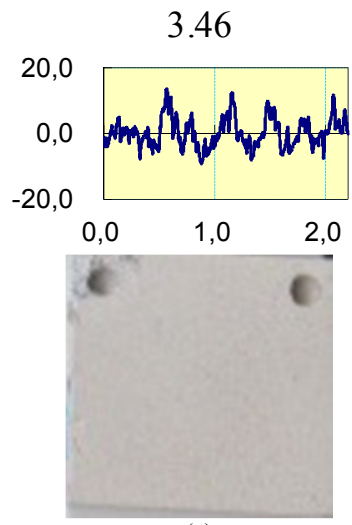

(a)

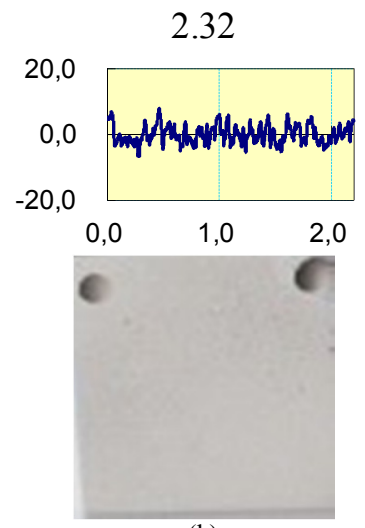

(b)
Fig. 4. Surface properties of the examined materials at: (a) $4.7 \mathrm{~m} / \mathrm{min}$, (b) $10 \mathrm{~m} / \mathrm{min}$

\section{Corrosion Test}

Immersion test results are shown in Figure 5. The corrosion rate of the rolled material at the rolling speed of $10 \mathrm{~m} / \mathrm{min}$ for the first 40 hours is faster than that of $4.7 \mathrm{~m} / \mathrm{min}$, but afterwards, the corrosion rate increased more in the $4.7 \mathrm{~m} / \mathrm{min}$ sample. The corrosion rate of the first 40 hours is under the influence of the coating. However, the corrosion rate was influenced by the properties of the base material in the following hours. Firstly, the relationship between corrosion rate and MAO coating was determined by the diameter and the number of pores of the coating. The more the pores or the 
larger the diameter, the faster the corrosion tendency. It is believed that the large diameter pores of the rolled material at $10 \mathrm{~m} / \mathrm{min}$ cause a high corrosion rate in the first 40 hours [8]. The corrosion attacks find a way to enter inside the coating due to the pores formed during MAO resulting in destruction of the coating layer. On the other hand, the degrading of coating firstly occurs in the porous/outer layer and after that the degrading encounters with the barrier/inner layer which is denser than the porous layer, wherein the corrosion rate is changed by the time of immersion. As seen in Figure 5, the $4.7 \mathrm{~m} / \mathrm{min}$ rolled sample had the most liner line, although the $10 \mathrm{~m} / \mathrm{min}$ rolled sample includes decreasing corrosion rate till 120 hours. The dense inner layer is the main determiner of the corrosion rate of the coating under increasing corrosion attacks with increasing immersion time [9]. However, it is known that the rolled materials at high speeds contain fewer twins and more recrystallized grains. It is reported that twinning adversely affects the corrosion resistance due to their different stress zones. However, the fact is that the recrystallized grains contain more grain boundaries and less dislocation density contributes to corrosion resistance [10]. The reason why corrosion resistance is weaker after 40 hours in the material with $4.7 \mathrm{~m} / \mathrm{min}$ rolling speed may be attributed to this.

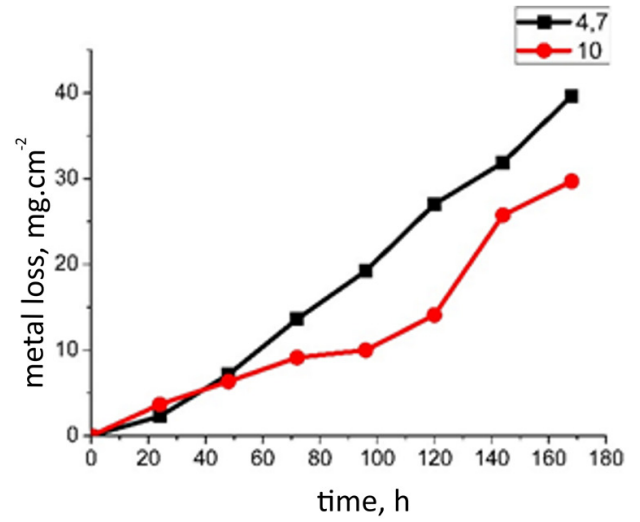

Fig. 5. Corrosion rates of samples that were corroded for 168 hours in $3.5 \% \mathrm{NaCl}$

\section{After Corrosion}

After the corrosion test, pictures and SEM images were taken from the surfaces of the materials and are exhibited in Figure 6. As it can be seen from the macro pictures and the SEM images, it is understood that the rolled material with a rolling speed of $4.7 \mathrm{~m} / \mathrm{min}$ has deeper and wider corrosion pits. As can be seen from Figure 7, $\mathrm{Mg}, \mathrm{O}$ and $\mathrm{Al}$ elements remain in the coating material. However, as it progresses towards the base material, $\mathrm{Mg}$ becomes more dominant. During corrosion, oxidation occurs on the surface of the material and forms a compound with $\mathrm{Al}$ and $\mathrm{Mg}$.

\section{CONCLUSION}

Corrosion resistance of $\mathrm{AZ3} 1 \mathrm{Mg}$ alloy with $0.5 \% \mathrm{La}$ was higher in the first 40 hours at of $4.7 \mathrm{~m} / \mathrm{min}$ rolling speed compared to the rolled material at $10 \mathrm{~m} / \mathrm{min}$ due to the size of micro pores which is narrower at $4.7 \mathrm{~m} / \mathrm{min}$. The following hours, the corrosion rate of $4.7 \mathrm{~m} / \mathrm{min}$ deteriorated by the twins dominated microstructure.

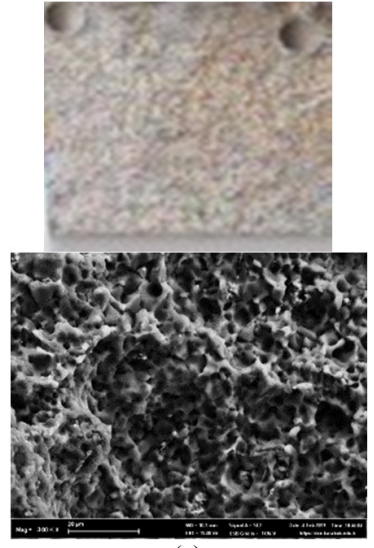

(a)

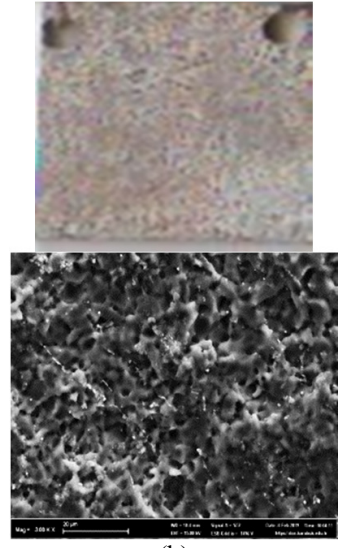

(b)
Fig. 6. SEM investigations after the corrosion test, (a) $4.7 \mathrm{~m} / \mathrm{min}$, (b) $10 \mathrm{~m} / \mathrm{min}$

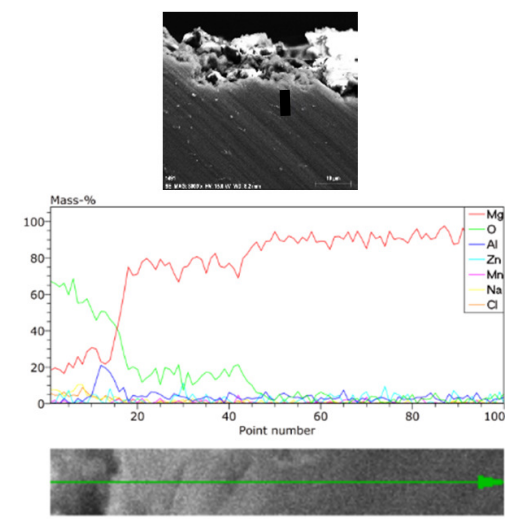

Fig. 7. Linear EDS analysis from section to base material after corrosion test for the 4.7 SP-MAO sample

\section{REFERENCES}

[1] X. Liu, B. W. Zhu, C. Xie, J. Zhang, C. P. Tang, Y. Q. Chen, "Twinning, dynamic recrystallization, and crack in AZ31 magnesium alloy during high strain rate plane strain compression across a wide temperature”, Materials Science and Engineering: A, Vol. 733, pp. 98107,2018

[2] J. B. Zhang, L. B. Tong, C. Xu, Z. H. Jiang, L. R. Cheng, S. Kamado, H. J. Zhang, "Influence of $\mathrm{Ca}-\mathrm{Ce} / \mathrm{La}$ synergistic alloying on the microstructure and mechanical properties of extruded $\mathrm{Mg}-\mathrm{Zn}$ alloy", Materials Science and Engineering: A, Vol. 708, pp. 11-20, 2017

[3] I. H. Kara, H. Ahlatci, Y. Turen, Y. Sun, "Microstructure and corrosion properties of lanthanum-added AZ31 Mg alloys", Arabian Journal of Geosciences, Vol. 11, No. 18, Article ID 535, 2018

[4] D. Sreekanth, N. Rameshbabu, K. Venkateswarlu, "Effect of various additives on morphology and corrosion behavior of ceramic coatings developed on AZ31 magnesium alloy by plasma electrolytic oxidation", Ceramics International,Vol. 38, No. 6, pp. 4607-4615, 2012

[5] Y. Du, M. Zheng, X. Qiao, W. Peng, B. Jiang, "Effect of La addition on the microstructure and mechanical properties of $\mathrm{Mg}-6 \mathrm{wt} \% \mathrm{Zn}$ alloys", Materials Science and Engineering: A, Vol. 673, pp. 47-54, 2016

[6] M. Mhaede, F. Pastore, B. Hadzima, "Influence of shot peening on corrosion properties of biocompatible magnesium alloy AZ31 coated by dicalcium phosphate dihydrate (DCPD)", Materials Science and Engineering: C,Vol. 39, pp. 330-335, 2014 
[7] V. Ezhilselvi, J. Nithin, J. N. Balaraju, S. Subramanian, "The influence of current density on the morphology and corrosion properties of MAO coatings on AZ31B magnesium alloy", Surface and Coatings Technology, Vol. 288, pp. 221-229, 2016

[8] A. Keyvani, M. Zamani, A. Fattah-Alhosseini, S. H. Nourbakhsh, M. Bahamirian, "Microstructure and corrosion resistance of MAO coatings on AZ31 magnesium", Materials Research Express, Vol. 5, Article ID 086510, 2018

[9] K. Dong, Y. Song, D. Shan, E. H. Han, "Corrosion behavior of a selfsealing pore micro-arc oxidation film on AM60 magnesium alloy", Corrosion Science,Vol. 100, pp. 275-283, 2015

[10] F. Guo, D. Zhang, X. Yang, L. Jiang, S. Chai, F. Pan, "Influence of rolling speed on microstructure and mechanical properties of AZ31 Mg alloy rolled by large strain hot rolling", Materials Science and Engineering: A,Vol. 607, pp. 383-389, 2014

\section{AUTHOR PROFILES}

Galal EImansouri was born in 1972 in Triboli and obtained his BSc degree from Libya. Presently, he is PhD student in the Department of Metallurgical and Materials Engineering, Faculty of Engineering, Karabuk University, Turkey.

Ismail Hakki Kara is a research assistant at Karabuk University, Turkey. He obtained his BSc degree from the Department of Metallurgical and Material Engineering, ITU, Istanbul, Turkey, in 2012. His research interests include welding technology, P91 and P92 steels, microstructure characterization, SEM, microscopy, and magnesium alloys.

Hayrettin Ahlatci, was born in 1969 in Karabuk and obtained his BSc degree from the Department of Metallurgical and Material Engineering, Istanbul Technical University (ITU), Turkey, in 1994. He started his academic career as a research assistant at Karaelmas University in Zonguldak, Turkey. He completed his $\mathrm{MSc}$ and $\mathrm{PhD}$ degrees at the Institute of Science at ITU. Presently, he is Associate Professor in the Department of Metallurgical and Materials Engineering, Faculty of Engineering, Karabuk University, Turkey.

Yunus Turen was born in 1965 in Karabuk and obtained his BSc degree from the Department of Metallurgical and Material Engineering, Gazi University, Turkey, in 1999. Presently, he is an Associate Professor in the Department of Metallurgical and Materials Engineering, Faculty of Engineering, Karabuk University, Turkey. 